\title{
Assessment of the Quality of Prenatal Consultations in the Regions of Kandi-Gogounou-Segbana in the Northern Benin \\ Lokossou MSHS ${ }^{1}$, Ogoudjobi OM ${ }^{1 *}$, Hounkpatin $B^{1}$, Vodouhe $M^{2}$, Salifou $K^{2}$, Komongui DG ${ }^{1}$, DES Sossa $I^{1}$, Lokossou $A^{1}$ and Perrin RX ${ }^{1}$ \\ ${ }^{1}$ Department of Health Sciences, University of Abomey-Calavi, Benin \\ ${ }^{2}$ Department of Medicine, University of Parakou, Benin
}

"Corresponding author: Ogoudjobi O. Mathieu, Assistant Professor of Obstetrics Gynecology, Department of Health Sciences, University of Abomey-Calavi, Benin, Tel: (229)97563303; E-mail: mogoudjobi2014@gmail.com

Received date: September 20, 2018; Accepted date: October 09, 2018; Published date: October 12, 2018

Copyright: (c) 2018 Lokossou MSHS, et al. This is an open-access article distributed under the terms of the Creative Commons Attribution License, which permits unrestricted use, distribution, and reproduction in any medium, provided the original author and source are credited.

\begin{abstract}
Introduction: Care during pregnancy is important for the health of the mother and the development of the unborn baby.

Objective: To evaluate the quality of Refocused Prenatal Consultations (RPNC) in one health zone of the Northern Benin.

Patients and methods: This is a prospective and evaluative study carried out from March $20^{\text {th }}$ to May $25^{\text {th }}, 2017$ in twelve health centers at the Kandi-Gogounou-Segbana health zone (KGS) in northern Benin. Sampling is systematic with extensive recruitment. The study included all midwives practicing in the study area and all pregnant women received by these midwives at one of the twelve public health centers of the KGS health zone during the study period. Each midwife and each pregnant woman are included after oral consent.

Results: The quality of the Prenatal Consultation (PNC) at the KGS health zone in the Northern Benin is unsatisfactory $(76.9 \%)$. Several steps of RPNC (Reception of pregnant, physical examination, tasks after examination, counseling/advices) were insufficiently executed. The best executed steps are Prevention care $(92.8 \%)$, prenatal check-up $(92.0 \%)$ and Interview/interrogation $(91.3 \%)$. The quality of the RPNC is compromised by the lack of control and monitoring of norms and standards in force in Benin.
\end{abstract}

Keywords: Prenatal consultations; Quality; Northern Benin

\section{Introduction}

Antenatal care is one of the four pillars of safe motherhood [1]. Their objectives are to prevent, detect early and manage complications that may affect the health of the mother and child to be born but also to accompany the mother and her relatives throughout the pregnancy [2].

A lot of investments in prenatal care have been made in developing countries, supported by hopes placed in the "risk approach". So much was invested that PNC has a real success with women in West Africa. In urban areas, $90 \%$ of pregnant women have at least one PNC and $80 \%$ have at least three [2]. In addition to the routine PNC, an updated antenatal care approach called refocused PNC or focused PNC has been introduced. It focuses on the quality of antenatal cares rather than their number.

In Benin, the authorities have taken a number of actions, including the implementation of free preventive care, such as the Expanded Program on Immunization (EPI), the subsidy for PNC activities, the Refocused Prenatal Consultations (RPNC) and staff training. According to the 2011-2012 Demographic Health Survey conducted in Benin [3], 86\% of pregnant women undergone prenatal consultations performed by trained staff in $86 \%$ of the cases. At the same time, maternal and neonatal mortality didn't decreased [4]. Our study therefore proposed to evaluate the quality of the RPNC of the KGS health zone.

\section{Patients and Study Methods}

This is a prospective and evaluative study carried out from March $20^{\text {th }}$ to May $25^{\text {th }}, 2017$ in twelve health centers at the KandiGogounou-Segbana health zone (KGS) in northern Benin.

The study population was midwives and pregnant women receiving at Refocused Prenatal Consultations (RPNC). Sampling is systematic with extensive recruitment. We included all midwives practicing in the study area and all pregnant women received by these midwives at one of the twelve public health centers of the KGS health zone during the study period.

The main variable of the study was the quality of refocused prenatal consultation. This quality was measured according to criteria $1,2,3,4,5,6,7,8,9$ and 10 taken from documents of the norms, procedures and standards of the PNC in Benin [5] (Table 1). Criteria 1 to 10 were identified as discriminatory and the quality of antenatal care was dependent on it. 
Citation: Lokossou MSHS, Ogoudjobi OM, Hounkpatin B, Vodouhe M, Salifou K, et al. (2018) Assessment of the Quality of Prenatal Consultations in the Regions of Kandi-Gogounou-Segbana in the Northern Benin. Clinics Mother Child Health 15: 303 . doi: $10.4172 / 2090-7214.1000303$

Page 2 of 5

\begin{tabular}{|c|c|}
\hline Criteria 1 & Greeting the patient, asking for the reason of her presence and providing her with a seat were all done by the service provider. \\
\hline Criteria 2 & The pregnancy term was specified against the date of the last periods or by using ultrasound; the probable date of delivery was calculated. \\
\hline Criteria 3 & $\begin{array}{l}\text { During each consultation: blood pressure and the temperature of the patients were taken; the search for mucous pallor and the urinary strip test } \\
\text { for glycosuria and albuminuria were performed and interpreted correctly. }\end{array}$ \\
\hline Criteria 4 & The weight, the check for abnormal weight change of the pregnant woman and the screening for an edema in the legs were realized. \\
\hline Criteria 5 & $\begin{array}{l}\text { All aspects of the obstetrical examination (breast examination, measurement of the uterine height, research of fetal pole, research and counting } \\
\text { of fetal heart sound, speculum examination, vaginal examination and pelvic assessment in the third trimester) were realized. }\end{array}$ \\
\hline Criteria 6 & $\begin{array}{l}\text { At the end of the examination: a general conclusion about the status of the pregnant woman was made; the prognosis of pregnancy was } \\
\text { specified; the pregnant woman was informed of the results of the examination. }\end{array}$ \\
\hline Criteria 7 & $\begin{array}{l}\text { Rhesus }(\mathrm{Rh}) \text { factor identification and blood type confirmation, level of hemoglobin, syphilitic serology and voluntary HIV testing were all } \\
\text { requested. }\end{array}$ \\
\hline Criteria 8 & Iron and Foldine supplementation, Mebendazole deworming and the pregnant woman's tetanus vaccination were carried out. \\
\hline Criteria 9 & A good intermittent preventive treatment of malaria with supervised intakes has been done in the absence of contraindication. \\
\hline Criteria 10 & $\begin{array}{l}\text { The pregnant woman got counseling on nutrition, awareness of the danger signs and the use of the (long-lasting insecticide-treated nets) } \\
\text { LLITNs, a delivery plan and an appointment. }\end{array}$ \\
\hline
\end{tabular}

Table 1: Definition of the quality criteria of the refocused PNC in Benin [5].

Data collection was done using a personal interview sheet and observation grid developed for this purpose. A documentary review from the maternal card and the health record of each pregnant woman at the end of the consultation completed the interview sheet. A gesture is validated when it is done. Each of the components of a criteria is considered good if the calculated score is $\geq 80 \%$ and unsatisfactory in the opposite case. The collected data are entered with the EXCEL version 2013 software. The data analysis was done using the software SPSS 20 and Epi info 3.5.3.

\section{Results}

At the end of our study, we recruited 200 pregnant women in the twelve health centers in the KGS health zone. These pregnant women were received in the various health centers by fourteen midwives.

\section{Socio-demographic profile of pregnant women}

About half of pregnant women (48.7\%) dah between 25 and 35 years, with a not negligible proportion under 25 years old (40.0\%). The average age was $26.31 \pm 6.62$ years with extremes of 14 and 46 years (Table 2). The pregnant women of the study were dominated by housewives (65.5\%), Muslim women (53.0\%). They were mostly out of school (62.5\%) and lived in rural areas (60.5\%).

\begin{tabular}{|l|l|l|}
\hline \multicolumn{2}{|l|}{ Effective (n=200) } & Percentage (\%) \\
\hline Age (year) & 82 & 41.0 \\
\hline Less than 25 & 95 & 47.5 \\
\hline $25-35$ & 23 & 11.5 \\
\hline 35 and over & \multicolumn{2}{|l|}{} \\
\hline Occupation & 131 & 65.5 \\
\hline Household & 18 & 9.0 \\
\hline Pupil/student & \multicolumn{2}{|l|}{} \\
\hline
\end{tabular}

\begin{tabular}{|c|c|c|}
\hline Shopkeeper & 25 & 12.5 \\
\hline Official & 6 & 3.0 \\
\hline Artisan/seamstress/dressing & 20 & 10.0 \\
\hline \multicolumn{3}{|l|}{ Religion } \\
\hline Christian & 86 & 43.0 \\
\hline Muslim & 106 & 53.0 \\
\hline Animist & 8 & 4.0 \\
\hline \multicolumn{3}{|l|}{ Level of education } \\
\hline Unschooled & 125 & 62.5 \\
\hline Primary & 43 & 21.5 \\
\hline Secondary & 24 & 12.0 \\
\hline Superior & 8 & 4.0 \\
\hline \multicolumn{3}{|l|}{ Middle of residence } \\
\hline Urban & 79 & 39.5 \\
\hline Rural & 121 & 60.5 \\
\hline
\end{tabular}

Table 2: Socio-demographic profile of pregnant women.

\section{Practice of refocused NPC step by step}

Overall, the quality of the RPNC practice was unsatisfactory with a score of $76.9 \%$. The observation rate for each stage of this prenatal consultation is as follows:

\section{Reception of the pregnant women}

The practice of step was observed according four items of criteria 1 (preparation of service, prepared aseptic device, greeting, giving seat) 
Citation: Lokossou MSHS, Ogoudjobi OM, Hounkpatin B, Vodouhe M, Salifou K, et al. (2018) Assessment of the Quality of Prenatal Consultations in the Regions of Kandi-Gogounou-Segbana in the Northern Benin. Clinics Mother Child Health 15: 303. doi: $10.4172 / 2090-7214.1000303$

Page 3 of 5

with an average score of $73.0 \%$ (Table 3 and Figure 1). Giving a seat and greeting were the most observed, respectively in $98.0 \%$ and $91.0 \%$.

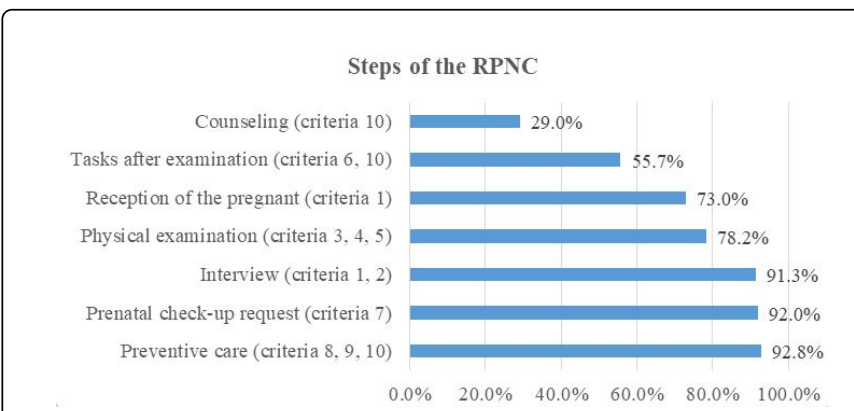

Figure 1: Achievement rate of the various steps of the RPNC (overall score $=76.9 \%$ ).

\section{Interview or interrogation}

The quality of interview was evaluated according one item of criteria 1 (request for complaints) and two items of criteria 2 (Date of last menstrual period, probable delivery date calculation). The practice of this step was observed on average in $91.3 \%$ (Table 3 and Figure 1). Request was the most observed with $100 \%$.

\begin{tabular}{|c|c|c|}
\hline & $\begin{array}{l}\text { Effective } \quad(n= \\
200)\end{array}$ & $\begin{array}{l}\text { Percentage } \\
\text { (\%) }\end{array}$ \\
\hline \multicolumn{3}{|l|}{ Criteria 1} \\
\hline Preparation of the service & 100 & 50.0 \\
\hline Prepared aseptic device & 106 & 53.0 \\
\hline Greeting of the pregnant & 182 & 91.0 \\
\hline Request for complaints & 200 & 100.0 \\
\hline Gives a seat to the pregnant & 196 & 98.0 \\
\hline \multicolumn{3}{|l|}{ Criteria 2} \\
\hline $\mathrm{DDR}^{*}$ request for the term of pregnancy & 174 & 87.0 \\
\hline Probable delivery date calculation & 174 & 87.0 \\
\hline \multicolumn{3}{|l|}{ Criteria 3} \\
\hline Taking blood pressure & 200 & 100.0 \\
\hline Taking the temperature & 110 & 55.0 \\
\hline $\begin{array}{l}\text { Looking for pallor of the mucous } \\
\text { membranes }\end{array}$ & 200 & 100.0 \\
\hline Urine strip test performed & 116 & 58.0 \\
\hline \multicolumn{3}{|l|}{ Criteria 4} \\
\hline Weight gain & 182 & 91.0 \\
\hline $\mathrm{IMO}^{* *}$ search & 196 & 98.0 \\
\hline
\end{tabular}

Table 3: Distribution of pregnant women according to criteria 1,2,3 and 4 .

\section{Physical examination}

Physical examination was evaluated on thirteen items by criteria 3,4 and 5 with an average score of $78.2 \%$ (Figure 1). Speculum examination $(21.0 \%)$ and pelvic exam $(38.0 \%)$ in third trimester are often not performed (Tables 3 and 4 ).

\section{Tasks after examination}

This step was evaluated by the items of criteria 6 and one item of criteria 10 (appointment given) with an average score of $55.7 \%$ (Figure 1 ). At the end of the clinical examination, midwives practically did not synthesize (41.0\%) and pregnancy prognosis (21.0\%) (Table 4).

\begin{tabular}{|c|c|c|}
\hline & Effective $(n=200)$ & $\begin{array}{l}\text { Percentage } \\
\text { (\%) }\end{array}$ \\
\hline \multicolumn{3}{|l|}{ Criteria 5} \\
\hline Breast examination & 144 & 72.0 \\
\hline Measurement of uterine height & 200 & 100.0 \\
\hline Research of fetal poles & 194 & 97.0 \\
\hline Auscultation of fetal heart sounds & 176 & 88.0 \\
\hline Speculum examination & 42 & 21.0 \\
\hline Vaginal touch & 198 & 99.0 \\
\hline Pelvic exam in third trimester & 76 & 38.0 \\
\hline \multicolumn{3}{|l|}{ Criteria } \\
\hline Conclusion made at the end of the exam & 82 & 41.0 \\
\hline Prognosis of pregnancy appreciated & 42 & 21.0 \\
\hline $\begin{array}{l}\text { Gestante informed of the results of the } \\
\text { examination }\end{array}$ & 138 & 69.0 \\
\hline \multicolumn{3}{|l|}{ Criteria } \\
\hline \multicolumn{3}{|l|}{ Prenatal check-up request } \\
\hline Blood group & 198 & 99.0 \\
\hline Blood count & 178 & 89.0 \\
\hline Syphilitic serology (TPHA,VDRL) & 172 & 86.0 \\
\hline HIV serology & 194 & 97.0 \\
\hline Toxoplasmosis, Rubella serology & 130 & 65.0 \\
\hline Obstetrical ultrasound & 172 & 86.0 \\
\hline
\end{tabular}

Table 4: Distribution of pregnant women according to criteria 5, 6 and 7.

\section{Prenatal check-up}

The prenatal check-up was evaluated according criteria 7. The practice of this step was observed on average in $92.0 \%$ (Figure1). The recommended paraclinical examinations were requested in the majority of the cases with a rate varying between $65.0 \%$ and $99.0 \%$ (Table 4). 
Citation: Lokossou MSHS, Ogoudjobi OM, Hounkpatin B, Vodouhe M, Salifou K, et al. (2018) Assessment of the Quality of Prenatal Consultations in the Regions of Kandi-Gogounou-Segbana in the Northern Benin. Clinics Mother Child Health 15: 303 . doi: $10.4172 / 2090-7214.1000303$

Page 4 of 5

\section{Preventive care}

The preventive care was evaluated according the three items of criteria 8 , the only item of criteria 9 and one item (impregnated mosquito net) with an average score of $92.8 \%$ (Figure 1). Iron supplement/folic acid (100\%), deworming (97.0\%) and vaccination against tetanus $94.0 \%$ ) was more observed (Table 5).

\begin{tabular}{|l|l|l|}
\hline \multicolumn{2}{|l|}{ Effective (n=200) } & Percentage (\%) \\
\hline Criteria 8 8 & 200 & 100.0 \\
\hline Iron Supplement/Folic acid & 194 & 97.0 \\
\hline Deworming & 188 & 94.0 \\
\hline Vaccination (VAT) & \multicolumn{2}{|}{} \\
\hline Criteria 9 malaria & 198 & 99.0 \\
\hline $\begin{array}{l}\text { Chemical prophylaxis of } \\
\text { (TPI/SP) }\end{array}$ & \multicolumn{2}{|l|}{} \\
\hline Criteria 10 & 58 & 29.0 \\
\hline Nutritional advice done & 86 & 43.0 \\
\hline Signs of danger explained & 148 & 74.0 \\
\hline Awareness on mosquito nets (MIILD) & 30 & 15.0 \\
\hline Established birth plan & 184 & 92.0 \\
\hline Appointment given &
\end{tabular}

Table 5: Distribution of pregnant women according to criteria 5, 6 and 7.

\section{Counseling/advices}

This stage of RPNC was observed in only $29 \%$ of cases (criteria 10 ) (Figure 1). The plan for delivery or birth plan was practically not realized $(15.0 \%)$ (Table 5).

\section{Discussion}

Several authors agree that it is the rigorous application of the RPNC's content by qualified health personnel working in optimal conditions that contribute to the achievement of maternal mortality and neonatal rate reduction. According to a study conducted in Guadeloupe, it has been shown that the number of PNC has little impact on the outcome of pregnancy [6].

In our study, the quality of the RPNC practice was unsatisfactory with a score of $76.9 \%$. Several unsatisfactory steps (Reception of pregnant, physical examination, tasks after examination, counseling/ advices) was insufficiently executed. This observation, although noted in Africa, varies from one country to another [4]. In Ethiopia [7], out of 823 pregnant women who received antenatal care, only one-third received prenatal care services of acceptable quality. In Zambia [8], $29 \%$ received good prenatal care and only $8 \%$ in the first trimester of pregnancy. This echoes the results of a multicenter study [9] that included 7 countries where for almost 14,000 clinical consultations, the quality of care for pregnant women was relatively low: providers performed only half or two-thirds of a minimum set of recommended clinical actions. The chances of receiving all prenatal care interventions increased significantly with higher levels of education and wealth status [4]. The pregnant women of our study were dominated by housewives $(65.5 \%)$. They were mostly out of school (62.5\%) and lived in rural areas $(60.5 \%)$. it is often a poor population with financial difficulties, hence the importance of the plan for delivery not to be surprised by expenses. Despite the characteristics of our study population, the plan for delivery or birth plan was practically not realized $(15.0 \%)$.

Hemorrhage and prematurity continue to be the leading causes of maternal and neonatal morbidity and mortality. The search for risk factors (multiparity, history of abortion, premature delivery, low socioeconomic level, etc.), lifestyle (precariousness, stress, overwork) and obstetrical history make it possible to assess the risk and therefore to put in place a more adequate and personalized surveillance.

The placement of the speculum makes it possible to identify the origin and assess the abundance of the bleeding. Moreover, this examination makes it possible to perform cervical cancer screening by inspection associated with visual inspection with acetic acid and visual inspection with lugol. In our study, the speculum was not of it was of weak realization $(21 \%)$. This finding was also made by Salifou, et al. [10], in 3 main maternity hospitals in northern Benin. The insufficiency of use of the speculum would be the reason.

It was also noted that pelvic examination in the third trimester of pregnancy was not conducted at about 6 pregnant women out of 10 (62\%). This situation explains the high rate of obstetric emergencies due to bone disorders in our formations due to the lack of achievement of the prognosis of delivery during the $3^{\text {rd }}$ trimester of pregnancy, with the consequent maternal morbidity caused by uterine rupture and emergency caesarean section $[11,12]$.

Serological examination during prenatal consultations is a good way of early detection of breast tumor. It was lacking in $1 / 4$ of the cases. In Morocco [13] more than half (51.5\%) of women in a health center said they did not receive a clinical breast examination by health professionals. The health worker is an important player in cancer prevention. These are opportunities missed by health professionals to inform, guide and screen women.

The calculation of the probable date of delivery allows from the date of the last menstrual period or the early ultrasound to avoid the errors of term thus reducing the risks of term overruns or premature deliveries but also prevent non-detection of a delayed growth. In our study, almost all pregnant women (87\%) benefited from it. Elsewhere in other Beninese studies, the situation is different $[10,14]$.

The information/education/communication component of antenatal care is an important aspect of programs aimed at reducing maternal and neonatal mortality. This criterion of the RPNC was was bad in our study (29\%). In Tanzania [15], only 54\% of pregnant women were able to cite at least one of the signs that give a hint that a pregnancy might be at risk. The birth plan, the danger signs should be discussed with the pregnant woman in the presence of her husband or a family member to avoid the first delay.

According to Dugas and Salifou, et al., intervention programs aimed at improving health literacy can improve the skills and health knowledge pregnant women have about pregnancy and prenatal care $[10,16]$. This participatory approach is effective and cost-effective in initiating behavioral and educational changes in mothers and has a positive impact on their attitudes towards health. 
Citation: Lokossou MSHS, Ogoudjobi OM, Hounkpatin B, Vodouhe M, Salifou K, et al. (2018) Assessment of the Quality of Prenatal Consultations in the Regions of Kandi-Gogounou-Segbana in the Northern Benin. Clinics Mother Child Health 15: 303. doi: $10.4172 / 2090-7214.1000303$

Page 5 of 5

\section{Conclusion}

This study revealed that the practice of RPNC is unsatisfactory in the health zone of Kandi-Gogounou-Segbana health zone (KGS) in northern Benin. The evaluation of the quality of antenatal care in health facilities is essential to detect deficiencies in the health system. Further study will identify these deficiencies in order to provide corrective measures (continuing education, audits).

\section{Ethical Aspects}

The study has been carried out with the approval of administrative authorities at different levels. Confidentiality and anonymity of the data have been respected. Each midwife and each pregnant woman are included after oral consent.

\section{Conflict of Interest}

The authors state that there is no conflict of interest.

\section{References}

1. WHO (2005) The World health report: 2005: make every mother and child count. Geneva: World Health Organization.

2. Prual A, de Bernis L, Ould D (2002) Role potentiel de la consultation prénatale dans la lutte contre la mortalité maternelle et mortalité néonatale en Afrique sub-saharienne. J Gynecol Obs Biol Reprod 31: 90-99.

3. Ministère du Développement, de l'Analyse Économique et de la Prospective: Institut National de la Statistique et de l'Analyse Économique (INSAE) (2017) Enquête Démographique et de Santé Bénin (EDSB-IV) 2011-2012.

4. Carvajal-Aguirre L, Amouzou A, Mehra V, Ziqi M, Zaka N, et al. (2017) Gap between contact and content in maternal and newborn care: An analysis of data from 20 countries in sub-Saharan Africa. J Glob Health 7: 1-8.

5. Ministère de la santé (2006) Direction de la santé familiale: normes et procédures de la santé de la reproduction au Bénin. Edit Cotonou 72.
6. Léticée N, Vendittelli F, Ughetto S, Janky E (2013) La qualité du suivi de la grossesse interfère-elle avec les issues de la grossesse, en Guadeloupe冈? Gynecol Obstet Fertil 41: 282-288.

7. Ejigu T, Woldie M, Kifle Y (2013) Quality of antenatal care services at public health facilities of Bahir-Dar special zone, Northwest Ethiopia. BMC Health Serv Res 13: 1.

8. Kyei N, Chansa C, Gabrysch S (2012) Quality of antenatal care in Zambia a national assessment. BMC Preg Childbirth 12: 151.

9. Kruk ME, Chukwuma A, Mbaruku G, Leslie HH (2017) Variation in quality of primary-care services in Kenya, Malawi, Namibia, Rwanda, Senegal, Uganda and the United Republic of Tanzania. Bull World Health Organ 95: 408-418.

10. Salifou K, Hounkpatin B, Hounkponou F, Obossou A, Sidi R, et al. (2014) Qualité de la consultation prénatale recentrée dans trois principales maternités de Parakou. Annales de la SOGGO 9:21-26.

11. Tchaou BA, Hounkponou NFM, Salifou K, Zoumenou E, Chobli M (2015) Les urgences obstétricales à l'Hôpital Universitaires de Parakou au Bénin: Aspects cliniques, thérapeutiques et évolutifs. Eur Sci J 11: 260272.

12. Lokossou MSH, Ogoudjobi OM, Tognifode V, Adisso S, Ali ARORS, et al. (2016) Les étiologies des urgences obstétricales à la maternité du centre Hospitalier Universitaire Départemental de l'Ouémé-Plateau (CHUD$\mathrm{OP})$ au Bénin. J de la Société Biologique et Clinique du Bénin 27: 52-58.

13. Al-sakkaf KA, Basaleem HO (2016) Breast Cancer Knowledge, Perception and Breast Self- Examination Practices among Yemeni Women囚: an Application of the Health Belief Model. Asian Pac J Cancer Prev 17: 1463-1467.

14. Saizonou J, Agueh DV, Aguemon B, Adé VM, Assavedo S, et al. (2014) Évaluation de la qualité des services de consultation prénatale recentrée à l'hôpital de district de Suru-Léré au Bénin. Sante Publique (Paris) 26: 249-257.

15. Sarker M, Schmid G, Larsson E, Kirenga S, De Allegri M, et al. (2010) Quality of antenatal care in rural southern Tanzania: a reality check. BMC Res Notes 3: 209.

16. Dugas M (2011) Donner aux populations vulnérables de l'Afrique subsaharienne un accès aux soins obstétricaux冈: Stratégie avancée de consultations prénatales. Med Trop 71: 526-528. 